\title{
Zijn extended-matching multiplechoicevragen geschikt voor een eindtoets?
}

\author{
J. Beullens, B. van Damme, H. Jaspaert, P.J. Janssen
}

\section{Samenvatting}

Inleiding: In de Faculteit Geneeskunde van de Katholieke Universiteit (KU) van Leuven wordt een eindtoets ontwikkeld die deels bestaat uit extended-matching multiplechoicevragen (EM). Elke EM-vraag omvat een thema, een lijst met antwoordmogelijkheden, een opdracht en één of meer ziektegeschiedenissen. Docenten uit tien medische disciplines leverden ongeveer negenhonderd items. Met een proeftoets is de kwaliteit van de vragen en de haalbaarheid van de afname nagegaan.

Methode: Negen reeksen van honderd vragen werden gepresenteerd in de vorm van viff boekjes met twintig vragen. 251 laatstejaarsstudenten geneeskunde kregen elk honderd EM-vragen aangeboden.

Resultaten: De afname verliep zonder problemen. Het bleek haalbaar honderd EM-vragen op een halve dag op te lossen. Vermoeidheid had geen meetbaar effect op de score. Er was wel een meetbaar effect van toenemende vertrouwdheid met de vraagvorm. Om zo betrouwbaar mogelijke reeksen te verkrijgen, werden de vragen die negatief correleerden met de totaalscore geschrapt tot een Cronbachs alfa van 0.80 werd bereikt. De face-validiteit werd nagegaan door afname van een vragenlijstje na het examen. Studenten oordeelden licht positief over instructies, toets en afname. De wijze waarop de toets werd samengesteld, leverde argumenten op voor de inhoudsvaliditeit. De correlaties met de totale examenuitslagen in voorgaande jaren van de medische opleiding waren over het algemeen behoorlijk. Dit pleit voor criteriumvaliditeit.

Conclusie: Het bleek mogelijk betrouwbare en valide eindtoetsen te ontwikkelen bestaande uit honderd EM-vragen. De toets kon binnen een halve dag afgenomen worden zonder dat er een meetbaar effect optrad van de vermoeidheid van de studenten. (Beullens J, Damme B van, Jaspaert H, Janssen PJ. Zijn extended-matching multiplechoicevragen geschikt voor een eindtoets? Tijdschrift voor Medisch Onderwijs 2002;21(3): 104-110.)

\section{Inleiding}

In het academiejaar 2000-2001 is aan de Katholieke Universiteit Leuven in het laatste jaar van de medische opleiding gestart met een onderwijsvorm die nieuw is voor zowel docenten als studenten: het probleemoplossingsgericht klinisch college. Verspreid over acht weken worden in het begin van het academiejaar ongeveer zeventig klinische colleges gegeven. Er wordt uitgegaan van één of meer schriftelijke, realistische ziektegeschiedenis(sen) met bijhorende opdrachten. Ter voor- bereiding op het college voeren de studenten, in kleine groepen (van ongeveer vijf studenten), deze opdrachten uit: de voorbereidende zelfstudie. De resultaten hiervan worden in de grote groep (ongeveer zeventig studenten) onder leiding van één of twee docenten besproken. De aandacht is vooral gericht op het klinisch redeneren en de verschillende oplossingen die dit oplevert. Er zijn steeds twee klinische colleges gepland in de namiddag. De studenten hebben de voormiddag vrij om zich op het college voor te bereiden. 
Deze onderwijsvernieuwing gaat gepaard met de introductie van een nieuwe examenvorm, bestaand uit extended-matching multiplechoicevragen (EM). ${ }^{1}$ Dit examen zal gelden als onderdeel van de eindtoets van de medische opleiding. Een EM-toets werd verkozen omdat deze de toepassing van kennis op ziektegeschiedenissen vergt en toelaat om in korte tijd een groot aantal vragen te stellen, wat de betrouwbaarheid en validiteit van het examen ten goede zou moeten komen. Een EM-vraag omvat vier componenten: een thema of probleem, een lijst met opties of antwoordmogelijkheden, een opdracht of vraag en itemstammen in de vorm van ziektegeschiedenissen. Voorbeelden van opties bij het thema 'vermoeidheid' zijn: anemie, depressie, hypothyroïdie, leukemie en Lyme-ziekte; de opdracht zou kunnen luiden: wat is de meest waarschijnlijke diagnose? De opties worden aangeduid met een letter van het alfabet, zodat het maximum aantal antwoordalternatieven 26 bedraagt. Het minimum aantal is zeven. Hierdoor wordt de kans op raden zodanig verkleind dat een correctie voor raden niet meer nodig is. Voor eenzelfde thema, optielijst en opdracht kunnen verschillende casussen geformuleerd worden.

Er is in de medisch-onderwijskundige literatuur weinig te vinden over de kwaliteit van EM-vragen. Case, Swanson en Ripley vergeleken multiplechoicevragen met vijf antwoordmogelijkheden met EMvragen met negen à 23 opties, die overigens identiek waren. ${ }^{2}$ Van achttien multiplechoicevragen en achttien EM-vragen was de generaliseerbaarheidscoëfficiënt respectievelijk 0.42 en 0.55 . Fenderson en medewerkers onderzochten verschillen tussen EM-vragen met twintig opties en multiplechoicevragen met vijf antwoordmogelijkheden. ${ }^{3}$ De interne consistentie (Cronbachs alfa) bedroeg 0.83 voor 240 multiplechoicevragen en 0.90 voor 220 EM-vragen.

Ter voorbereiding op het examen werd een proeftoets van negenhonderd vragen samengesteld. Op 3 maart 2000 werd deze proeftoets afgenomen bij 251 laatstejaarsstudenten. Deze proeftoets werd georganiseerd om de praktische haalbaarheid van een dergelijke afname na te gaan en de psychometrische kwaliteit van de vragen te onderzoeken. De vragen werden gepresenteerd in reeksen van honderd. De onderzoeksvragen waren: (1) Is het praktisch haalbaar om honderd EM-vragen af te nemen op een halve dag? (2) Zijn de vragenreeksen intern consistent en betrouwbaar? (3) Hoe is het gesteld met de face-, inhouds- en begripsvaliditeit?

\section{Methode}

\section{Deelnemers}

Aan de proeftoets werd deelgenomen door 251 laatstejaarsstudenten geneeskunde. Deelname was verplicht. 27 afwezigen hadden hun afwezigheid gewettigd.

\section{Procedure van toetsontwikkeling}

De EM-vragen werden opgesteld door docenten uit tien specialismen. Hun werd gevraagd per discipline een lijst op te stellen van de (meest) frequente klinische problemen waarmee zij in de beroepspraktijk geconfronteerd werden. Hiervan diende een lijst met relevante ziektetoestanden afgeleid te worden. Van elke ziektetoestand moesten vervolgens de aspecten aangeduid worden die relevant waren voor de zevendejaarsstudent (bijvoorbeeld diagnose, therapie). Voor sommige aspecten diende het niveau van kennen en kunnen verder gespecificeerd te worden (bijvoorbeeld een grondige kennis omtrent de differentiële diagnose, oppervlakkige kennis omtrent de behandeling). Als hulpmiddel ontvingen de docenten de 
disciplinegebonden eindtermen van het Raamplan 1994. ${ }^{4}$ Elke discipline diende dus uit te gaan van een blauwdruk, gevormd door de dimensies ziektetoestanden en te behandelen aspecten.

Het vertrekpunt voor de eigenlijke formulering van de EM-vragen vormde een introductiedag met 'writing parties', geleid door Case en Swanson van de National Board of Medical Examiners (NBME). De disciplines waren verder vrij autonoom in hun organisatie van de schrijfgroepen en de samenstelling van hun deel van de toets. Er werd niet gecontroleerd in welke mate de aanbevolen procedure gevolgd werd.

De tien medische disciplines werden ingedeeld in vijf disciplinegroepen: de vier grote disciplines (inwendige geneeskunde, pediatrie, heelkunde en gynaecologie/verloskunde) en 'groep 5' (de overige disciplines samen). Per disciplinegroep werd een coördinator aangewezen. De taken van de coördinator bestonden uit het verzamelen van de vragen, de eerste beoordeling van de vragen en, indien nodig, terugzending naar de ontwikkelaar(s) ter verbetering. In tweede instantie werden de vragen beoordeeld, bijgeschaafd en eventueel teruggezonden naar de betreffende coördinator door medewerkers van de Onderwijskundige Dienst (OD). De vragen werden in een centraal bestand van de OD opgenomen. Deze vragenbank kwam slechts moeizaam tot stand. Het gewenste aantal tweehonderd vragen per disciplinegroep werd niet gehaald.

\section{Organisatie van de afname}

De vragen werden gegroepeerd in negen reeksen. Elke reeks bestond uit vijf boekjes met twintig vragen. Elk van de 45 boekjes bevatte vragen uit de vier grote disciplines (inwendige geneeskunde, pediatrie, heelkunde, gynaecologie/verlos- kunde), waarvoor veel vragen beschikbaar waren, en uit de pool van vragen uit de andere disciplines. Er werd over gewaakt dat elk boekje een toevallige variatie bevatte aan thema's (behandelde problemen) en aspecten (diagnose, therapie, et cetera). Elke student vulde één reeks van honderd EM-vragen in. De studenten waren niet voorbereid op de inhoud en de vorm van de vragen. Na elk item werd het oordeel van de student gevraagd over de relevantie ervan voor de praktijk van de basisarts. Zij konden dit aangeven op een zespuntsschaal van 'niet relevant' tot 'zeer relevant'. Na de proeftoets gaven de studenten, met behulp van een zespuntsschaal van 'helemaal niet akkoord' tot 'helemaal akkoord', hun oordeel over negen beweringen omtrent instructies, proeftoets en toetsafname. Deze beweringen komen overeen met negen voorwaarden voor adequaat examineren, te weten doelstellingenvaliditeit, normering, generaliseerbaarheid, respect, objectiviteit, standaardisatie, evaluatietransparantie, betrouwbaarheid en acceptatie. ${ }^{5}$

De toetsafname had gelijktijdig plaats in drie auditoria. Om individueel werken te bevorderen werd aan elke zijde en voor en achter de student een vrije plaats voorzien. De instructies werden bij aanvang omgeroepen. Dertig medewerkers hielpen bij het verdelen en ophalen van de boekjes. Voor elke student was een envelop voorzien met vijf boekjes uit dezelfde reeks. De medewerker nam een willekeurig boekje uit de envelop en was er verantwoordelijk voor dat het ingevulde boekje ingeleverd werd voordat de student een pauze nam. Aangezien de afname quasi anoniem was bevatten boekjes en antwoordbladen van elke student een codenummer. In het begin van de voormiddag werd een aanwezigheidslijst ingevuld. De studenten kregen aan het eind van het jaar, onder code- 
nummer, feedback in de vorm van een vergelijking van hun individuele prestaties met de prestaties van de gehele groep. De sleutel werd slechts verbroken na beëindiging van het academiejaar, zodat de resultaten van deze proeftoets niet konden interfereren met de eigenlijke examenresultaten.

\section{Statistische analyse}

De mogelijke rol van vermoeidheid werd ingeschat met behulp van variantieanalyse. Nagegaan werd wat de invloed was van de volgorde van de boekjes op de score per boekje. Om de mogelijkheid van een leereffect na te gaan werd op vergelijkbare wijze gekeken naar de tijd die nodig was om het boekje in te vullen. De praktische haalbaarheid werd beoordeeld over de gehele proeftoets. Aangezien elke student slechts één reeks vragen invulde, werden de betrouwbaarheid en validiteit voor elk van de negen reeksen afzonderlijk berekend. Om een voldoende interne consistentie te bereiken werden items geschrapt die negatief correleerden met de totaalscore per reeks, tot een Cronbachs alfa van 0.80 werd bereikt. Gemiddelde scores werden berekend voor de vragenlijst betreffende het oordeel van de student over de proeftoets en voor de vragen over de relevantie van de EM-vragen voor de praktijk van de basisarts. Deze scores werden beschouwd als aanwijzingen voor face-validiteit. De werkwijze die gevolgd was bij de samenstelling van de proeftoets leverde argumenten op voor de inhoudsvaliditeit. De begripsvaliditeit werd verder nagegaan door Pearson product-moment-correlatiecoëfficiënten te berekenen tussen de toetsscores per reeks en de totale examenuitslag in elk van de zeven jaren van de medische opleiding. Verschillen tussen de negen reeksen werden op hun significantie getoetst met behulp van variantie- analyses. Bij de beoordeling van de bevindingen werd het 5\%-significantieniveau gehanteerd.

\section{Resultaten}

\section{Haalbaarheid}

De afname verliep vlot, van de toevallige toewijzing van de plaatsen en het geven van instructies tot het invullen van de vragenlijst achteraf. Zoals gepland volstonden vier uren om de proeftoets af te nemen. De gemiddelde tijd om een boekje in te vullen bedroeg 32.3 minuten (standaarddeviatie (SD) 9.4 minuten; mediaan 31 minuten). De studenten hadden dus gemiddeld ongeveer anderhalve minuut nodig om een EM-vraag te beantwoorden. Het gemiddelde percentage juiste antwoorden per student bedroeg 53.2\% (SD $7.8 \%$; mediaan $53 \%$ ). De volgorde waarin de boekjes werden ingevuld had geen significante invloed op het percentage juiste antwoorden (ANOVA, p>0.05). De tijd nodig om een boekje in te vullen daalde wel significant naarmate de proeftoets vorderde (ANOVA, $\mathrm{p}<0.001$ ).

\section{Betrouwbaarheid}

Elk van de negen reeksen vragen werd opgelost door 27, 28 of 29 studenten. Het aantal vragen per reeks dat voldeed aan de kwaliteitscriteria lag tussen 73 en 90 omdat vragen die negatief correleerden met de totaalscore per reeks verwijderd werden tot een interne consistentie (Cronbachs alfa) van 0.80 werd bereikt (tabel 1). Het gemiddeld percentage juiste antwoorden per reeks lag tussen 51.11 en 57.30 (tabel 1). Het verschil in moeilijkheidsgraad ( $\mathrm{p}$-waarde) tussen de reeksen was niet significant (ANOVA, $\mathrm{p}>0.05$ ).

\section{Validiteit}

De score op de vragenlijst betreffende het oordeel over de proeftoets werd als een eer- 
Tabel 1. Resultaten per reeks.

\begin{tabular}{llllll}
\hline Reeks & $\begin{array}{l}\text { Aantal } \\
\text { studenten }\end{array}$ & $\begin{array}{l}\text { Aantal } \\
\text { vragen* }\end{array}$ & $\begin{array}{l}\text { Aantal juiste } \\
\text { antwoorden } \\
\text { per student }\end{array}$ & $\begin{array}{l}\text { Standaard- } \\
\text { deviatie }\end{array}$ & Mediaan \\
\hline $\mathrm{a}$ & 27 & 88 & 57.30 & 9.84 & 55.06 \\
$\mathrm{~b}$ & 27 & 77 & 51.85 & 10.31 & 51.28 \\
$\mathrm{C}$ & 29 & 73 & 51.11 & 9.95 & 52.05 \\
$\mathrm{~d}$ & 28 & 90 & 51.94 & 10.09 & 52.22 \\
$\mathrm{e}$ & 28 & 87 & 54.84 & 10.09 & 54.02 \\
$\mathrm{f}$ & 27 & 80 & 54.17 & 10.29 & 53.75 \\
$\mathrm{~g}$ & 29 & 75 & 53.75 & 10.66 & 54.67 \\
$\mathrm{~h}$ & 28 & 76 & 54.56 & 10.88 & 53.29 \\
$\mathrm{i}$ & 28 & 78 & 53.11 & 10.09 & 53.85 \\
\hline
\end{tabular}

* na verwijdering van de items met een negatieve discriminatiewaarde.

ste indicator van de face-validiteit beschouwd. Aangezien de studenten noch op de inhoud, noch op de vorm van de vragen waren voorbereid, werd geen uitgesproken positief oordeel verwacht. De gemiddelde score van 3.81 op een zespuntsschaal wijst op een licht positieve houding. De studenten oordeelden positief over de 'duidelijke instructies', 'gelijke afnameomstandigheden', 'kans speelt geen rol' en 'zwaarte van de toets'. De studenten hadden echter bedenkingen bij de praktische relevantie, representativiteit voor de medische opleiding, objectiviteit van de toets als maat van inmiddels verworven eigen competentie, mogelijkheid te tonen wat men kan en aanvaardbaarheid als eindtoets. Per vragenreeks varieerde de gemiddelde score tussen 3.58 en 4.02. Deze verschillen waren evenwel niet significant (ANOVA, $\mathrm{p}>0.05$ ).

Het oordeel over de relevantie van elk item vormde een tweede indicator voor de face-validiteit. Een gemiddelde van 3.76 op een zespuntsschaal en een mediaan van 3.79 wezen eveneens op een licht positief oordeel. Deze score schommelde per reeks tussen 3.52 en 3.87. Opnieuw waren de verschillen niet significant (ANOVA, 0.1 $>\mathrm{p}>0.05$ ).
Ter evaluatie van de begripsvaliditeit werd het verband nagegaan met behaalde examenresultaten. De Pearsoncorrelaties tussen de toetsscores per reeks en de totale examenscore voor elk van de zeven jaren van de gevolgde medische opleiding waren middelmatig tot zwak, maar statistisch significant (tabel 2). Deze correlaties varieerden van reeks tot reeks en van jaar tot jaar maar waren over het algemeen behoorlijk, hetgeen criteriumvaliditeit aannemelijk maakt.

\section{Discussie}

De afname van honderd EM-vragen op één voormiddag bleek haalbaar te zijn. Gemiddeld hadden de studenten anderhalve minuut nodig om een vraag te beantwoorden. De vertrouwdheid met de voor de studenten onbekende vraagvorm nam toe tijdens de afname, want de tijd nodig om een boekje in te vullen daalde significant van het eerste tot het vijfde boekje. Dit wijst op een leereffect. De score per boekje werd niet beïnvloed door toenemende vermoeidheid, aangezien de volgorde van de boekjes geen significante invloed had op het percentage correcte antwoorden. 
Tabel 2. Pearson correlaties van de toetsscores met de totale examenresultaten in elk jaar van de medische opleiding.

\begin{tabular}{lccccccc}
\hline Reeks & Jaar 1 & Jaar 2 & Jaar3 & Jaar 4 & Jaar 5 & Jaar 6 & Jaar 7 \\
\hline $\mathrm{a}$ & 0.55 & 0.63 & 0.56 & 0.56 & 0.55 & 0.50 & 0.35 \\
$\mathrm{~b}$ & 0.55 & 0.34 & 0.58 & 0.67 & 0.63 & 0.62 & 0.35 \\
$\mathrm{c}$ & 0.20 & 0.40 & 0.40 & 0.49 & 0.39 & 0.37 & 0.38 \\
$\mathrm{~d}$ & 0.54 & 0.76 & 0.77 & 0.75 & 0.76 & 0.52 & 0.67 \\
$\mathrm{e}$ & 0.59 & 0.57 & 0.57 & 0.53 & 0.58 & 0.57 & 0.64 \\
$\mathrm{f}$ & 0.52 & 0.28 & 0.49 & 0.51 & 0.59 & 0.45 & 0.47 \\
$\mathrm{~g}$ & 0.53 & 0.27 & 0.44 & 0.46 & 0.39 & 0.49 & 0.52 \\
$\mathrm{~h}$ & -0.29 & -0.24 & 0.17 & 0.08 & 0.21 & 0.42 & 0.56 \\
$\mathrm{i}$ & 0.25 & 0.27 & 0.42 & 0.43 & 0.54 & 0.38 & 0.47 \\
\hline
\end{tabular}

Na verwijdering van items die verkeerd discrimineerden waren er negen betrouwbare reeksen (Cronbachs alfa 0.80). De negen reeksen verschilden ook niet in moeilijkheidsgraad. In een werkelijk examen met een beperkt aantal vragen zou de inhoudsvaliditeit in het gedrang kunnen komen als er veel items geschrapt worden: de resterende vragen voldoen niet aan de blauwdruk en dus wordt de validiteit bedreigd. Een oplossing is het gebruik van een groot aantal items. De betrouwbaarheid is dan groter en psychometrisch zwakke items kunnen zonder probleem geschrapt worden. Een betere oplossing is verbetering van de kwaliteit van de toetsvragen. In een ander onderzoek werd bij 220 EM-vragen een Cronbachs alfa bereikt van $0.90 .{ }^{3}$ Wij zijn van plan tweehonderd vragen in het examen op te nemen.

De gemiddelde scores op de vragenlijst betreffende het oordeel van de studenten over de proeftoets en op de vragen na elk item over de relevantie voor de praktijk van de basisarts wezen op een licht positief oordeel. Een dergelijke houding ligt voor de hand omdat de studenten voor het eerst geconfronteerd werden met dit vraagtype en ook inhoudelijk niet voorbereid waren op deze proeftoets. Het begrip basisarts was wellicht onvoldoende helder gedefinieerd voor de studenten. Dit alles leidde mee tot de invoering van een introductiedag voor studenten. Een betere voorbereiding (evaluatietransparantie) kan een gunstige invloed hebben op de face-validiteit. Noch voor perceptie, noch voor relevantie was het verschil tussen de negen reeksen significant.

Als bij de ontwikkeling van de vragen de voorgestelde blauwdruk - relevante aspecten van frequente klinische problemen - gevolgd is, is de proeftoets inhoudsvalide. Het is evenwel niet duidelijk in hoeverre de docenten de aanbevolen procedure gevolgd hebben. De gevolgde werkwijze waarborgde in ieder geval dat de items afkomstig waren uit tien domeinen van de geneeskunde en een waaier van klinische problemen en uiteenlopende aspecten betroffen. Dit zijn aanwijzingen voor hun inhoudsvaliditeit. Of het gehele domein van wat relevant is voor de praktijk van de basisarts gedekt werd, is daarmee evenwel niet bewezen. De inhouds- en face-validiteit kunnen wellicht verhoogd worden door de docenten te vragen bij de voorbereiding van elk klinisch college EM-vragen samen te stellen. De begripsvaliditeit lijkt aannemelijk gemaakt door de significante correlaties tussen de toetsscore per reeks en de totale examenscore voor elk jaar van de medische opleiding. 
Een onverwacht bijkomend innovatief effect van het samenstellen van de toetsvragen was dat de docenten hun isolement als vakdeskundig examinator doorbraken en bereid waren hun vragen aan collega's voor te leggen ter beoordeling en bespreking.

De resultaten van dit onderzoek tonen aan dat een toets met honderd EM-vragen praktisch uitvoerbaar, betrouwbaar en valide kan zijn.

\section{Literatuur}

1. Case SM, Swanson DB. Constructing written test questions for the basic and clinical sciences. Philadelphia: National Board of Medical Examiners; 1996.

2. Case SM, Swanson DB, Ripkey DR. Comparison of items in five-option and extended-matching formats for assessment of diagnostic skills. Acad Med 1994;69(10 Suppl):S1-S3.

3. Fenderson BA, Damjanov I, Robeson MR, Veloski JJ, Rubin E. The virtues of extended matching and uncued tests as alternatives to multiple choice questions. Hum Pathol 1997;28:526-32.

4. Metz JCM, Pels Rijcken-Van Erp Taalman Kip EH, Brand-Valkenburg BWM van den. Raamplan
1994 artsopleiding: eindtermen van de artsopleiding. Nijmegen: Universitair Publikatiebureau Katholieke Universiteit Nijmegen; 1994.

5. Janssen PJ. Als examinator slagen in eigen examineren: aspecten van examineerexpertise. Tijdschrift voor Onderwijsrecht en Onderwijsbeleid 1999/2000(6):444-59.

De auteurs:

J. Beullens is psycholoog en wetenschappelijk medewerker aan de Onderwijskundige Dienst van de Faculteit Geneeskunde van de Katholieke Universiteit Leuven.

Prof. dr. B. van Damme is vice-decaan van de Faculteit Geneeskunde van de KU Leuven en hoofd van de dienst Pathologische Ontleedkunde.

Prof. dr. H. Jaspaert, pedagoog, is hoofddocent en leidt de Onderwijskundige Dienst van de Faculteit Geneeskunde van de KU Leuven.

Prof. dr. P. J. Janssen is emeritus gewoon hoogleraar in de Faculteit Psychologie en Pedagogische Wetenschappen van de KU Leuven en als extern consulent betrokken bij dit onderzoek.

\section{Correspondentieadres:}

Johan Beullens, Onderwijskundige Dienst Faculteit Geneeskunde, KU Leuven, Minderbroedersstraat 17, B3000 Leuven, België, Johan.Beullens@med.kuleuven. ac.be.

\section{Summary}

Introduction: At the Faculty of Medicine of the K.U. Leuven, Belgium, a final test is being developed which includes extended-matching multiple choice questions (EMQ's). These are problem oriented questions referring to a realistic case, with answers to be selected from a list of alternatives. Faculty from ten medical specialities developed about 900 questions. The quality and feasibility of the test were investigated by a pilot test.

Method: Nine series of one hundred questions were presented in five fascicles of twenty questions each. 251 final year students were presented with one hundred questions each.

Results: The test procedure proved to be feasible. One hundred EMQs could be answered within four hours. Fatigue had no measurable effect on the scores. Increasing familiarity with the question format was observed. A reliable series of questions was obtained by removing questions correlating negatively with the total score until Cronbach's alpha was 0.80. A questionnaire measuring students' perceptions of the test indicated a rather moderate face validity. Content validity was supported by the test construction procedure. Criterion validity was indicated by the observed correlation between test scores and total examination scores in each of the preceding years of medical education.

Conclusion: The results of the pilot test indicate that the EMQ-test was reliable and valid. A test time of four hours did not lead to a measurable effect of fatigue on students' test scores. EMQs appear to be appropriate for a final test in undergraduate medical education. (Beullens J, Damme B van, Jaspaert H, Janssen PJ. Are extended-matching multiple choice items suitable for a final test? Dutch Journal of Medical Education 2002;21(3): 104-110.) 